\title{
The Implications of Complete Mesocolic Excision in the Treatment of Patients with Potentially Curable Colorectal Cancer Stage III
}

\author{
AHMED S.A. ABDUL SAMAD, M.Sc.; MOSTAFA A. SOLIMAN, M.D.; \\ MAMDOH H. HAGGAG, M.D. and TAREK O. HEGAZY, M.D. \\ The Department of General Surgery, Faculty of Medicine, Cairo University
}

\begin{abstract}
Background: Complete mesocolic excision and central vascular ligation remove more mesocolon and are best able to completely remove lymph node metastases in the draining area raising a question, does it really improve the outcome compared to an incomplete or damaged excision of the mesentery.
\end{abstract}

Aim of the Work: To determine the drawbacks of total mesocolic excision on the number of total LNs harvested, overall survival and disease specific survival of Patients with Potentially Curable Colorectal Cancer Stage III.

Patients and Methods: It is a randomized control study and it's managed and followed-up in the police authority hospital between January 2014 and August 2015 (20 months), comparing it with a retrospective cohort (control) study of 55 patients that was analyzed in the previous study.

Twenty five patients with colon cancer stage III were included in the study with complete open resection of the primary tumour with lymphovascular resection as much as possible (complete mesocolic excision) to see its reflection on prognosis and follow-up of these patients for 18 months regarding survival rate, local recurrences, metastasis.

Results: The total number of harvested nodes was (505) LNs mean was $20.2 \pm 6.6$ (range 12-35, median 19 nodes). The total number of the positive LN was 129 ; its mean was $5.1 \pm 2$ (range 1-9, median 5). The number of patients with N1 was $6(24 \%)$, with N2a was $13(52 \%)$ and with N2b was $6(24 \%)$. The lymph node ratio ranged from $8.3 \%$ to $53.3 \%$ (mean $27.3 \pm 13.2$, median 25)

Comparing the 1.5 year overall and disease specific survival in colon cancer in both retrospective(control group) and prospective group revealed a better outcome in the prospective group in both OS and DSS (96\%) vs. (OS of $93.1 \%$, DSS of $90.9 \%$ ) in retrospective group, but it didn't reach a significance $(p=0.61)$ in OS and $(p=0.43)$ in DSS.

Correspondence to: Dr. Ahmed S.A. Abdul Samad, The Department of General Surgery, Faculty of Medicine, Cairo University
Conclusion: Extended lymphadenectomy in colon cancer is important and should be applied universally for several reasons as Tumor staging would be more precise and confounding stage migration is avoided.

Key Words: Complete mesocolic excision - Colorectal cancer.

\section{Introduction}

IN the surgical treatment of colorectal carcinoma, total mesorectal excision, multivisceral en-bloc resection of cT4 colon carcinomas, and the avoidance of tears or incisions of the tumor have been accepted as common principles for more than 20 years. Recently, the significance of the circumferential resection margin was acknowledged, and finally the quality of dissection, first along the mesorectal fascia [1] and recently along the surface of the mesocolon both of which derive from the same embryologic plane [2].

Metastatic tumor islands may be located right below mesorectal and mesocolic fascia and opening them up would mean a high risk of tumor spread. The safest technique is to preserve the entire mesocolon, including its fascia, by dissecting it as far centrally as possible, with high tie of the feeding vessels, and leaving behind only short vascular stumps and preserving the hypogastric nerve plexuses located immediately around the superior mesenteric artery and aorta. The specimen is retrieved as a package lined with peritoneum and intact fascia containing all the blood vessels, lymphatic vessels, and lymph nodes through which the tumor may disseminate [3].

An extended lymphadenectomy, however, does not have disadvantages for the patient like increased 
complication rates [4]. The increased number of negative lymph nodes with CME and central vascular ligation has been linked to improved survival in both lymph node-negative cases [5] and stage III disease [2].

Recent advances in the management of colon cancer identify total mesocolic excision as a potential determinant of survival following oncological resection. In 2009, Prof. Hohenberger proposed Complete Mesocolic Excision (CME) as a standardized surgical technique, in which the same principle of Total Mesorectal Excision (TME) in rectal cancer was to be applied to the colon. He recommended that the operation be performed using a surgical plane based on embryonic anatomy that is, a high-quality radical operation obtaining an optimal oncological pathological specimen, especially in the interperitoneal colon [6] .

\section{Patients and Methods}

The prospective group is enrolled in a Randomized Control Study and it's managed and followed-up in the police authority hospital between January 2014 and August 2015 (20 months).

25 patients with colon cancer stage III were included in the study with complete open resection of the primary tumour with lymphovascular resection as much as possible (complete mesocolic excision) to allow determination of a valuable ratio of lymph nodes to see its reflection on prognosis and follow-up of these patients for 18 months regarding survival rate, local recurrences, metastasis and its relation to gained lymph node ratio versus the affected number of lymph nodes.

\section{Inclusion criteria:}

All patients with a diagnosis of colon adenocarcinoma who are classified as stage III according to 7 th edition of AJCC cancer staging manual [7], and had undergone complete resection of the primary tumour (R0) were considered eligible for the study.

\section{Exclusion criteria:}

Patients with rectal tumors or who have fewer than 12 lymph nodes in the resected surgical specimen were excluded, in accordance with the best recommendations [7]. Also patients with positive macroscopic or microscopic residual tumor (R1, R2) were excluded from this study, Patients with HNCRC or who have carcinomas associated to inflammatory bowel disease, Sarcomas, lymphomas, and carcinoid tumors were considered ineli- gible in this study. Patients surviving less than a month were excluded from the study.

\section{Operative technique for the prospective group:}

Right hemicolectomy: High ligation of the main feeding arteries and Complete Mesocolic Excision (CME), Resection of the right colon involves resection of the ileocolic artery and right colic artery at their origin from the superior mesenteric artery. We usually ligate only the right branch of the middle colic artery, although the lymph nodes around the root of the middle colic artery are dissected.

In cases of tumors arising from the hepatic flexure of the colon, the middle colic artery is ligated flush to its taking off the SMA. (Extended right colectomy).

Left hemicolectomy and sigmoidectomy is done by ligating the IMA $1 \mathrm{~cm}$ to its origin from the aorta (leaving its ${ }^{1 \text { st }}$ branch intact) to ensure good vascularity of the anastomosis, protecting sympathetic plexus on the aorta, although the lymph nodes around the root of the inferior mesenteric artery are dissected.

Metastatic tumor islands may be located right below mesorectal and mesocolic fascia and opening them up would mean a high risk of tumor spread, so the safest technique is Complete Mesocolic Excision (CME) to preserve the entire mesocolon, including its fascia, by dissecting it as far centrally as possible, with high tie of the feeding vessels, and leaving behind only short vascular stumps and preserving the hypogastric nerve plexuses located immediately around the superior mesenteric artery and aorta. This is done by mesofacial sharp separation (separating the visceral fascia (deep mesenteric leaf) from parietal fascia covering the retroperitoneal structures).

The specimen is retrieved as a package lined with peritoneum and intact fascia containing all the blood vessels, lymphatic vessels, and lymph nodes through which the tumor may disseminate.

\section{Results}

Twenty five patients with colon cancer stage III were subjected to complete mesocolic excision (resection of the mesocolon as much as possible without compromising the vascularity of adjacent colon segments) to confirm the proven hypothesis in the retrospective cohort study that as long as the total number of resected LNs increased will decrease the lymph node ratio with subsequent improved overall and disease specific survival. 
Making the retrospective sample as a control group (ruling out patients with rectal cancer to minimize the statistical bias as we didn't change the technique of total mesorectal excision which is already done in the retrospective group).

The total number of harvested nodes was (505) LNs mean was $20.2 \pm 6.6$ (range $12-35$, median 19 nodes). The total number of the positive $\mathrm{LN}$ was 129 ; its mean was $5.1 \pm 2$ (range 1-9, median 5). The number of patients with N1 was $6(24 \%)$, with $\mathrm{N} 2 \mathrm{a}$ was $13(52 \%)$ and with $\mathrm{N} 2 \mathrm{~b}$ was $6(24 \%)$. The lymph node ratio ranged from $8.3 \%$ to $53.3 \%$ (mean 27.3 \pm 13.2 , median 25).

Comparing the 1.5 year overall and disease specific survival in colon cancer in both retrospective and prospective group revealed a better outcome in the prospective group in both OS and DSS $(96 \%)$ vs. (OS of $93.1 \%$, DSS of $90.9 \%$ ) in retrospective group, but it didn't reach a significance $(p=0.61)$ in OS and $(p=0.43)$ in DSS.
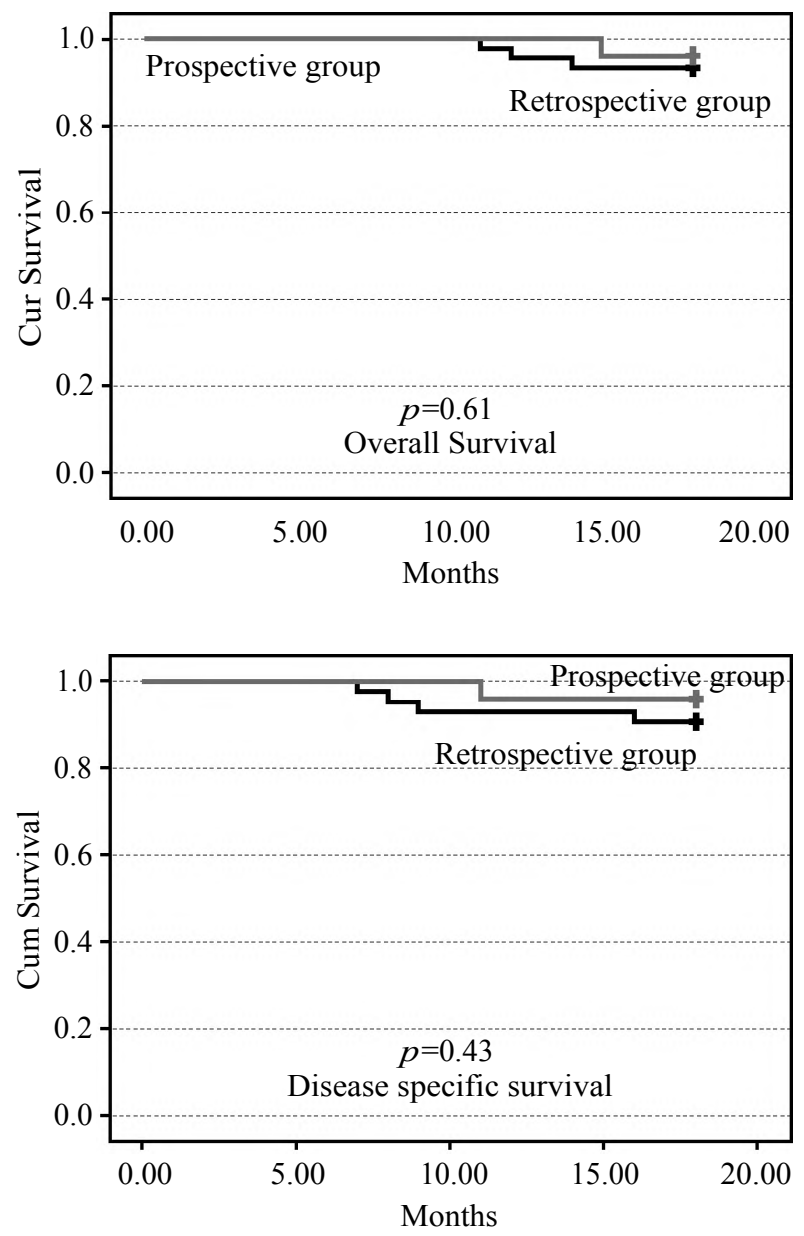

Fig. (1): 1.5 year overall and disease specific survival rates in 25 patients in prospective group and 44 patients in retrospective group stage III colon cancer underwent curative surgery.
Table (1): Clinicopathological characteristics of colon cancer patients stage III underwent curative resection (25 cases).

\begin{tabular}{|c|c|c|c|c|}
\hline & Number & $\begin{array}{l}\text { Percen- } \\
\text { tage (\%) }\end{array}$ & $\begin{array}{l}\text { Mean } \\
\pm \mathrm{SD}\end{array}$ & Range \\
\hline \multicolumn{5}{|l|}{ Age: } \\
\hline$\leq 60$ & $20 / 25$ & 80 & $52.5 \pm 8.6$ & $38-65$ \\
\hline$>60$ & $5 / 25$ & 20 & & \\
\hline \multicolumn{5}{|l|}{ Gender: } \\
\hline Male & 14 & 56 & - & - \\
\hline Female & 11 & 44 & - & - \\
\hline \multicolumn{5}{|l|}{ Site of tumor: } \\
\hline Left \& sigmoid colon & 14 & 56 & - & - \\
\hline Right colon & 8 & 32 & - & - \\
\hline Transverse colon & 3 & 12 & - & - \\
\hline \multicolumn{5}{|l|}{ TNM: } \\
\hline IIIA & 6 & 24 & - & - \\
\hline IIIB & 11 & 44 & - & - \\
\hline IIIC & 8 & 32 & - & - \\
\hline \multicolumn{5}{|l|}{ Tstage: } \\
\hline $\mathrm{T} 1$ & 2 & 8 & & \\
\hline $\mathrm{T} 2$ & 9 & 36 & & \\
\hline $\mathrm{T} 3$ & 9 & 36 & & \\
\hline $\mathrm{T} 4$ & 5 & 20 & & \\
\hline \multicolumn{5}{|l|}{ N stage: } \\
\hline N1 & 6 & 24 & - & - \\
\hline $\mathrm{N} 2 \mathrm{a}$ & 13 & 52 & - & \\
\hline $\mathrm{N} 2 \mathrm{~b}$ & 6 & 24 & - & \\
\hline Total LNs & 505 & - & $20.2 \pm 6.6$ & $12-35$ \\
\hline Positive LNs & 129 & - & $5.1 \pm 2$ & $1-9$ \\
\hline \multicolumn{5}{|l|}{ LNR: } \\
\hline$\leq 20 \%$ & 11 & 44 & $27.3 \pm 13.2$ & $8.3 \%-53.3 \%$ \\
\hline$>20 \%$ & 14 & 56 & & \\
\hline \multicolumn{5}{|l|}{ Grade: } \\
\hline Low & 15 & 60 & - & - \\
\hline High & 10 & 40 & - & - \\
\hline \multicolumn{5}{|l|}{ Type of tumour: } \\
\hline Mucous-producing & 14 & 56 & - & - \\
\hline Non mucous producing & 11 & 44 & - & - \\
\hline
\end{tabular}

Table (2): Survival analysis in 44 patients (retrospective group) and 25 patients (prospective group) with stage III colon cancer underwent curative surgery.

\begin{tabular}{|c|c|c|c|c|c|c|}
\hline & \multicolumn{2}{|c|}{ Study } & \multirow{2}{*}{$\begin{array}{l}\text { Hazard } \\
\text { ratio }\end{array}$} & \multicolumn{2}{|c|}{$95 \%$ CI HR } & \multirow{2}{*}{$\begin{array}{c}p- \\
\text { value }\end{array}$} \\
\hline & $\begin{array}{l}\text { Retro- } \\
\text { spective }\end{array}$ & $\begin{array}{l}\text { Pros- } \\
\text { pective }\end{array}$ & & Lower & Upper & \\
\hline - Overall survival & $\begin{array}{l}3 / 44 \\
93.1 \%\end{array}$ & $\begin{array}{l}1 / 25 \\
96 \%\end{array}$ & 1.76 & 0.184 & 16.97 & 0.61 \\
\hline $\begin{array}{l}\text { - Disease specific } \\
\text { survival }\end{array}$ & $\begin{array}{l}4 / 44 \\
90.9 \%\end{array}$ & $\begin{array}{l}1 / 25 \\
96 \%\end{array}$ & 2.35 & 0.263 & 21.04 & 0.43 \\
\hline
\end{tabular}


(A)
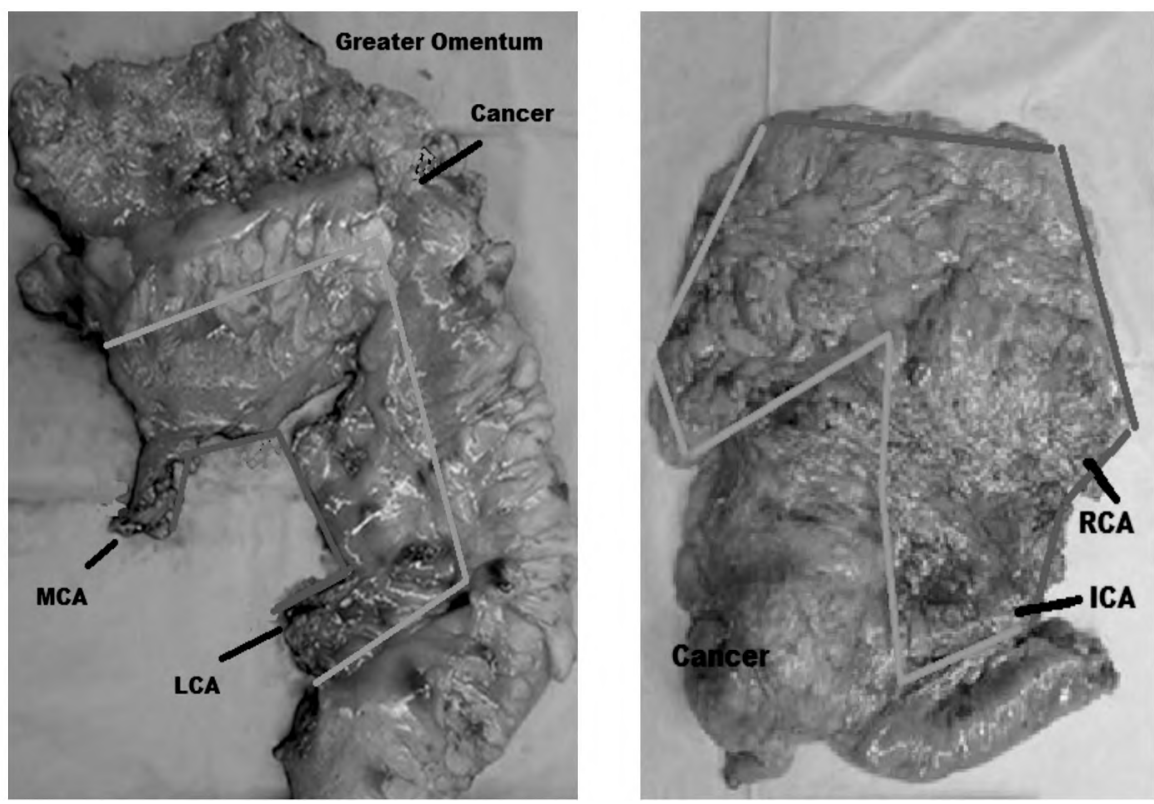

(B)

Fig. (2): Complete mesocolic excision of (A) A splenic flexure tumour showing the extension of mesocolon, LCA: Left Colic Artery, MCA: Middle Colic Artery. (B) Cancer coecum with mesocolic extension ICA: Ileocolic Artery, RCA: Right Colic Artery.

\section{Discussion}

Nodes are essential for accurate staging in CRC. $\mathrm{LN}$ recovery has consistently been at less than recommended levels in many institutions, with only $37 \%$ of CRC resection cases without neoadjuvant therapy reporting recovery of at least 12 LNs in the surveillance epidemiology and end results database [8]

It has been postulated that the number of metastatic nodes may increase as $\mathrm{LN}$ removal increases [9]. If so, extended lymphadenectomy designed to increase the number of negative nodes should not have a meaningful effect on patient outcome. Indeed, the probability of a $\mathrm{LN}$ to be positive depends on tumor biology and tumor-host interactions and not on number of resected nodes [10], and this is the case with complete mesocolic excision in our study showing us that extended lymphadenectomy is associated with better disease specific survival and overall survival despite the minimal increase in positive LNs yielded.

Moreover, Johnson et al., have demonstrated that the number of negative nodes is independently associated with improved long-term survival in metastatic node colon cancers, indirectly confirming the importance of LNR [11]. In agreement with previous series, in our study the number of metastatic nodes did increase with an increase in LN number. However, patients with fewer than 12 nodes showed a significantly lower number of positive nodes, suggesting that an adequate lym- phadenectomy is mandatory to correctly stage patients $[12,13]$.

ROC analysis selected 11 lymph nodes to be the cutoff value of DSS and OS significance, coherent with reports indicating that at least $14 \mathrm{LNs}$ have to be harvested to adequately stage colon cancers [14]; and 12 lymph nodes as recommended by the American Joint of Cancer Committee.

Reviewing our data, we did not find by univariate analysis a significant correlation between the total number of LNs resected and the survival rate of the patients ( $p=0.15$ for DSS \& $p=0.33$ for OS). This is likely to reflect the high standards of lymphadenectomy, with few patients in this population being understaged. Our findings are consistent with another study conducted using Surveillance, Epidemiology and End Results (SEER) data, which included records from four different hospitals [12] But our findings in the prospective complete mesocolic excision group showed us an outcome benefit regarding both DSS and OS compared with the control group, however, it didn't reach a significance ( $p=0.61$ for OS and $p=0.43$ for DSS).

\section{References}

1- QUIRKE P., STEELE R., MONSON J., et al.: Effect of the plane of surgery achieved on local recurrence in patients with operable rectal cancer: A prospective study using data from the MRC CR07 and NCIC-CTG CO16 randomised clinical trial. Lancet, 373: 821-8, 2009.

2- WEST N.P., HOHENBERGER W., WEBER K., et al.: Complete mesocolic excision with central vascular ligation 
produces an oncologically superior specimen compared with standard surgery for carcinoma of the colon. J. Clin. Oncol., 28: 272-8, 2010

3- HERMANN KESSLER and WERNER HOHENBERGER: Extended Lymphadenectomy in Colon Cancer is Crucial. World J. Surg., 37: 1789-98, 2013.

4- CAPLIN S., CEROTTINI J.P., BOSMAN F.T., et al.: For patients with Dukes' B (TNM stage II) colorectal carcinoma, examination of six or fewer lymph nodes is related to poor prognosis. Cancer, 83: 666-72, 1998.

5- CHEN S.L. and BILCHIK A.J.: More extensive nodal dissection improves survival for stages I-III of colon cancer: A populationbased study. Ann. Surg., 244: 602$10,2006$.

6- HOHENBERGER W., WEBER K., MATZEL K., PAPADOPOULOS T. and MERKEL S.: Standardized surgery for colonic cancer: Complete mesocolic excision and central ligation-technical notes and outcome. Colorectal Dis., 11: 354-64, 2009.

7- EDGE S.B., BYRD D.R., COMPTON C.C., FRITZ A.G., GREENE F.L. and TROTTI A. (eds).: AJCC Cancer Staging Manual (Seventh Edition). Chicago. Springer, 14: 160-73, 2010.

8- HOWLADER N., NOONE A.M., KRAPCHO M., GARSHELL J., et al. (eds).: Surveillance Epidemiology and End Results. Bethesda MD. SEER Stat Fact Sheets: Colon and Rectum. National Cancer Institute. Updated
2014. http://seer.cancer.gov/statfacts/html/colorect.html Accessed 20th April 2014

9- De RIDDER M., VINH-HUNG V., VAN NIEUWENHOVE Y., et al.: Prognostic value of the lymph node ratio in node positive colon cancer. Ann. Surg. Oncol., 55: $1681,2006$.

10- Le VOYER T.E., SIGURDSON E.R., HANLON A.L., et al.: Colon cancer survival is associated with increasing number of lymph nodes analyzed: A secondary survey of intergroup trial INT-0089. J. Clin. Oncol., 21: 2912-9, 2003.

11- JOHNSON P.M., PORTER G.A., RICCIARDI R., et al.: Increasing negative lymph node count is independently associated with improved long-term survival in stage IIIB and IIIC colon cancer. J. Clin. Oncol., 24: 3570-5, 2006

12-WONG S.L., JI H., HOLLENBECK B.K., MORRIS A.M., BASER O. and BIRKMEYER J.D.: Hospital lymph node examination rates and survival after resection for colon cancer. J.A.M.A., 298: 2149-54, 2007.

13- ROSENBERG R., FRIEDERICHS J., SCHUSTER T., et al.: Prognosis of patients with colorectal cancer is associated with lymph node ratio: A single-center analysis of 3,026 patients over a 25 -year time period. Ann. Surg. Dec., 248 (6): 968-78, 2008.

14- WANG J., HASSETT J.M., DAYTON M.T. and KULAYLAT M.N.: Lymph node ratio: Role in the staging of node-positive colon cancer. Ann. Surg. Oncol. Jun., 15 (6): 1600-8, 2008

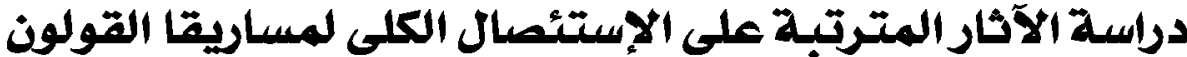

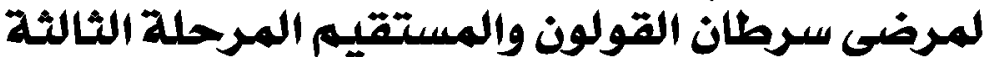 والتى يتهم معالجتها جرالياحيا}

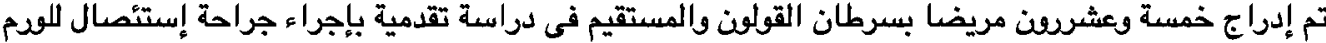

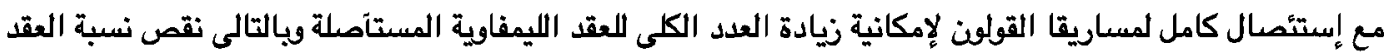

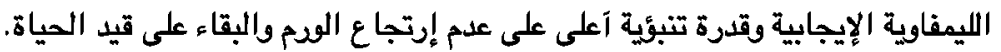

$$
\begin{aligned}
& \text { وقد آثبتت النتائج آن الإستئصال الكامل لمساريقا القولون مصاحب لنسبة آقل لإرتجاع الودم ونسبة آكثر اللبقاء } \\
& \text { على قيد الحياة. }
\end{aligned}
$$

